\title{
Shear wave elastography and Doppler ultrasound in kidney transplant recipients
}

Elastografia por onda de cisalhamento e ultrassom Doppler em pacientes renais pós-transplantados

\section{Luana Marinho Gonçalves ${ }^{1, a}$, Gabriele Carra Forte ${ }^{1, b}$, Tiago Garcia Holz ${ }^{1, c}$, Lucas Lobraico Libermann ${ }^{1, d}$, Carlos Eduardo Poli de Figueiredo ${ }^{1, e}$, Bruno Hochhegger ${ }^{1, f}$}

1. Pontifícia Universidade Católica do Rio Grande do Sul (PUCRS), Porto Alegre, RS, Brazil.

Correspondence: Gabriele Carra Forte. Pontifícia Universidade Católica do Rio Grande do Sul. Avenida Ipiranga, 6690, $1^{\circ}$ andar, Partenon. Porto Alegre, RS, Brazil, 90610-000. Email: gabicarraforte@yahoo.com.br.

a. https://orcid.org/0000-0002-6623-0736; b. https://orcid.org/0000-0002-1480-8196; c. https://orcid.org/0000-0002-3604-9565; d. https://orcid.org/0000-0003-3432-2262; e. https://orcid.org/0000-0002-7333-8884; f. https://orcid.org/0000-0003-1984-4636.

Received 2 October 2020. Accepted after revision 23 March 2021.

How to cite this article:

Gonçalves LM, Forte GC, Holz TG, Libermann LL, Poli de Figueiredo CE, Hochhegger B. Shear wave elastography and Doppler ultrasound in kidney transplant recipients. Radiol Bras. 2022 Jan/Fev;55(1):19-23.

Abstract Objective: To evaluate the association between shear wave elastography parameters and arterial resistance in kidney transplant recipients.

Materials and Methods: This was a prospective cross-sectional study involving consecutive adult kidney transplant recipients. All patients underwent color Doppler to evaluate the resistive index (RI) and ultrasound shear wave elastography for the quantification of renal allograft stiffness.

Results: We evaluated 55 patients, of whom 9 (16.4\%) had an RI defined as abnormal ( $\geq 0.79)$ and 46 (83.6\%) had an RI defined as normal (<0.79). The mean age was higher in the abnormal RI group than in the normal RI group (68.0 \pm 8.6 years vs. $42.6 \pm 14.1$ years; $p<0.001)$, as was the mean shear wave velocity $(2.6 \pm 0.4 \mathrm{~m} / \mathrm{s}$ vs. $2.2 \pm 0.4 \mathrm{~m} / \mathrm{s} ; p=0.013)$. Multivariate analysis identified two independent predictors of arterial resistance: age $(\mathrm{OR}=1.169 ; 95 \% \mathrm{Cl}: 1.056$ to $1.294 ; p=0.003)$ and shear wave velocity $(\mathrm{OR}$ $=17.1 ; 95 \% \mathrm{Cl}: 1.137$ to $257.83 ; p=0.040$ ).

Conclusion: We observed an association between rigidity in the cortex of the transplanted kidney, as evaluated by shear wave elastography, and arterial resistance, as evaluated by color Doppler, in kidney transplant recipients.

Keywords: Kidney transplantation; Elasticity imaging techniques; Ultrasonography, Doppler, color.

Resumo Objetivo: Avaliar a associação entre parâmetros de elastografia por onda de cisalhamento e resistência arterial em pacientes transplantados renais.

Materiais e Métodos: Estudo transversal prospectivo. 0 estudo incluiu de forma consecutiva indivíduos adultos transplantados renais. Foram coletados dados demográficos e clínicos. Todos os pacientes foram submetidos à técnica ultrassonográfica para avaliação do índice de resistência (IR) e à quantificação da elasticidade do tecido por ondas de cisalhamento para avaliar a rigidez do aloenxerto renal.

Resultados: Foram avaliados 55 pacientes. A média de idade e a velocidade da onda de cisalhamento foram maiores em pacientes com IR $\geq 0,79$ (respectivamente, $68,0 \pm 8,6$ anos e 2,6 $\pm 0,4 \mathrm{~m} / \mathrm{s}$ ) quando comparados a pacientes com IR $<0,79$ (respectivamente, 42,6 $\pm 14,1$ anos, $p<0,001$ e 2,2 $\pm 0,4 \mathrm{~m} / \mathrm{s}, p=0,013)$. A análise multivariada identificou a idade (OR = 1,169, IC 95\%: $1,056$ a 1,294; $p=0,003$ ) e a velocidade da onda de cisalhamento (OR = 17,1, IC 95\%: 1,137 a 257,83; $p=0,040)$ como fatores independentes associados a resistência arterial.

Conclusão: Observou-se associação entre a rigidez do córtex do transplante renal avaliada por elastografia por onda de cisalhamento e a resistência arterial em pacientes pós-transplantados renais avaliados por Doppler.

Unitermos: Transplante renal; Técnicas de imagem de elasticidade; Doppler.

\section{INTRODUCTION}

Kidney transplantation is considered the procedure of choice for patients with end-stage renal disease, prolonging survival and reducing costs ${ }^{(1)}$. Worldwide, the incidence of end-stage renal disease in all age groups increased by $34.4 \%$ between 1990 and $2017^{(2)}$. In Brazil, there were more than 10 million newly reported cases of chronic kidney disease, as well as nearly 36,000 deaths related to the disease, in 2017. Due to its high cost, renal replacement therapy is still of limited availability in many regions of the world. In contrast, kidney transplantation is cost-effective, regardless of the donor type ${ }^{(3)}$.

Regarding the diagnosis of chronic nephropathy, renal biopsy remains the gold standard procedure. Nonetheless, there are biopsy-related risks, such as chronic allograft injury, and there is broad variation in interobserver agree- 
ment among pathologists ${ }^{(4)}$. In addition, in an outpatient setting, renal allograft function is assessed by using a multimodal approach, including Doppler ultrasound examination, clinical evaluation, and analysis of laboratory results. However, none of those tests alone is specific enough to detect incipient dysfunction of a renal allograft ${ }^{(5)}$.

Doppler ultrasound is currently the noninvasive method of choice for the evaluation of pathological alterations in the kidneys and has been widely used in the assessment of renal allograft status ${ }^{(6-8)}$. Ultrasound has certain advantages, including the fact that it is readily available at most imaging centers, as well as having been proven safe and being a low-cost method ${ }^{(6,7)}$. However, the usefulness of the resistive index (RI) in predicting acute rejection is still under debate because of its low diagnostic performance, which is due to the influence of extrarenal factors ${ }^{(8,9)}$.

Morphological imaging of the renal allograft is performed mainly by B-mode ultrasound, computed tomography, or magnetic resonance imaging. However, structural evaluation of the renal parenchyma continues to be a challenge ${ }^{(10)}$. Ultrasound elastography has emerged as a tool to assist in the assessment of tissue stiffness, is already in use at major centers around the world, and has been the subject of a series of recent studies in the radiology literature of Brazil ${ }^{(11-15)}$. Shear wave elastography (SWE) is the most effective noninvasive technique for assessing renal fibrosis after transplantation ${ }^{(16)}$ and assessing tissue velocity in response to a low-frequency pulse, a low velocity being indicative of tissue stiffness ${ }^{(17)}$. The use of SWE can reveal significant differences between allograft stability and acute or chronic allograft dysfunction ${ }^{(16)}$.

To our knowledge, there have been few studies evaluating the association between ultrasound elastography and Doppler ultrasound in kidney transplant recipients, especially in Brazil. Therefore, the aim of this study was to evaluate the association between SWE parameters and arterial resistance in kidney transplant recipients in Brazil.

\section{MATERIALS AND METHODS}

This was a prospective cross-sectional study. The study protocol was approved by the Research Ethics Committee of the Pontifical Catholic University of Rio Grande do Sul (Reference no. 93226218.2.0000.5336), in the city of Porto Alegre, RS, Brazil. All of the authors signed a confidentiality agreement to ensure the anonymity of the data obtained from the electronic medical records of the hospital, and all participating patients gave written informed consent. The study was conducted in accordance with the guidelines set forth in the Declaration of Helsinki, and the article was prepared in accordance with The Strengthening the Reporting of Observational Studies in Epidemiology statement ${ }^{(18)}$.

The study included consecutive adult kidney transplant recipients who were referred to an outpatient nephrology clinic in southern Brazil for ultrasound imaging evaluation. Patients who had stage $\mathrm{V}$ chronic kidney disease and were on dialysis were excluded, as were those who had been diagnosed with hydronephrosis and those who were in their second or third trimester of pregnancy.

We collected demographic data (sex, age, and ethnicity) and clinical data (donor type, glomerular filtration rate, renal function, kidney size, and serum creatinine level). All patients underwent color Doppler to determine the RI and SWE for the assessment of renal allograft stiffness (quantification of the tissue elasticity). All ultrasound and SWE scans were performed by a board-certified radiologist, with eight years of experience, who was blinded to the clinical and biochemical profiles of the patients.

\section{Ultrasound examination}

Ultrasound examinations were performed with a portable, stand-alone ultrasound system (Aplio 300; Toshiba Medical Systems, Otawara, Japan), a 3-5 MHz convex transducer, and a 5-14 MHz linear transducer. All patients were examined in the supine position. The length of the transplanted kidney was measured by B-mode ultrasound. Color Doppler was used in order to evaluate tissue perfusion and to calculate the RI for the transplanted kidney:

$$
\begin{gathered}
R I=(\text { peak systolic velocity }- \text { end-diastolic velocity }) / \text { peak } \\
\text { systolic velocity }
\end{gathered}
$$

Intrarenal Doppler of the segmental arteries was performed at three representative locations (Figure 1), and the average was used for statistical analysis.

\section{Kidney stiffness measurement}

The SWE method generates shear waves within the tissue by using the radiation force of a focused ultrasound beam, and the propagation of the shear wave is monitored in order to quantify tissue stiffness. Young's modulus, measured in kilopascals, is the measure used for allograft stiffness, in which higher values correlate with a higher degree of fibrosis ${ }^{(19-21)}$. The SWE measurements were obtained in a single region of interest (ROI): an area of renal parenchyma. The distance from the skin to the ROI was recorded as kidney depth. All patients were examined between 8:00 a.m. and 10:00 a.m., on an empty stomach and in the supine position. The study was conducted under controlled conditions. The ROI was positioned perpendicular to the surface closest to the skin, with minimal compression of the transducer to avoid external compression of the transplanted kidney, followed by activation of the tissue image quantification mode with the acquisition of the shear wave velocity in the ROI, which was displayed on a color-coded map. Thirteen quantification cursors were placed within the ROI in the renal cortex, each providing the values for shear wave velocity (in meters per second) and elasticity (in kilopascals). The stiffness of the renal cortex of the transplanted kidney was calculated by determining the average values for the shear wave velocity and elasticity (Figure 2). 
Figure 1. Spectral color Doppler for evaluation of the RI of the interlobar artery.

Figure 2. SWE of the right parenchyma of a renal allograft.
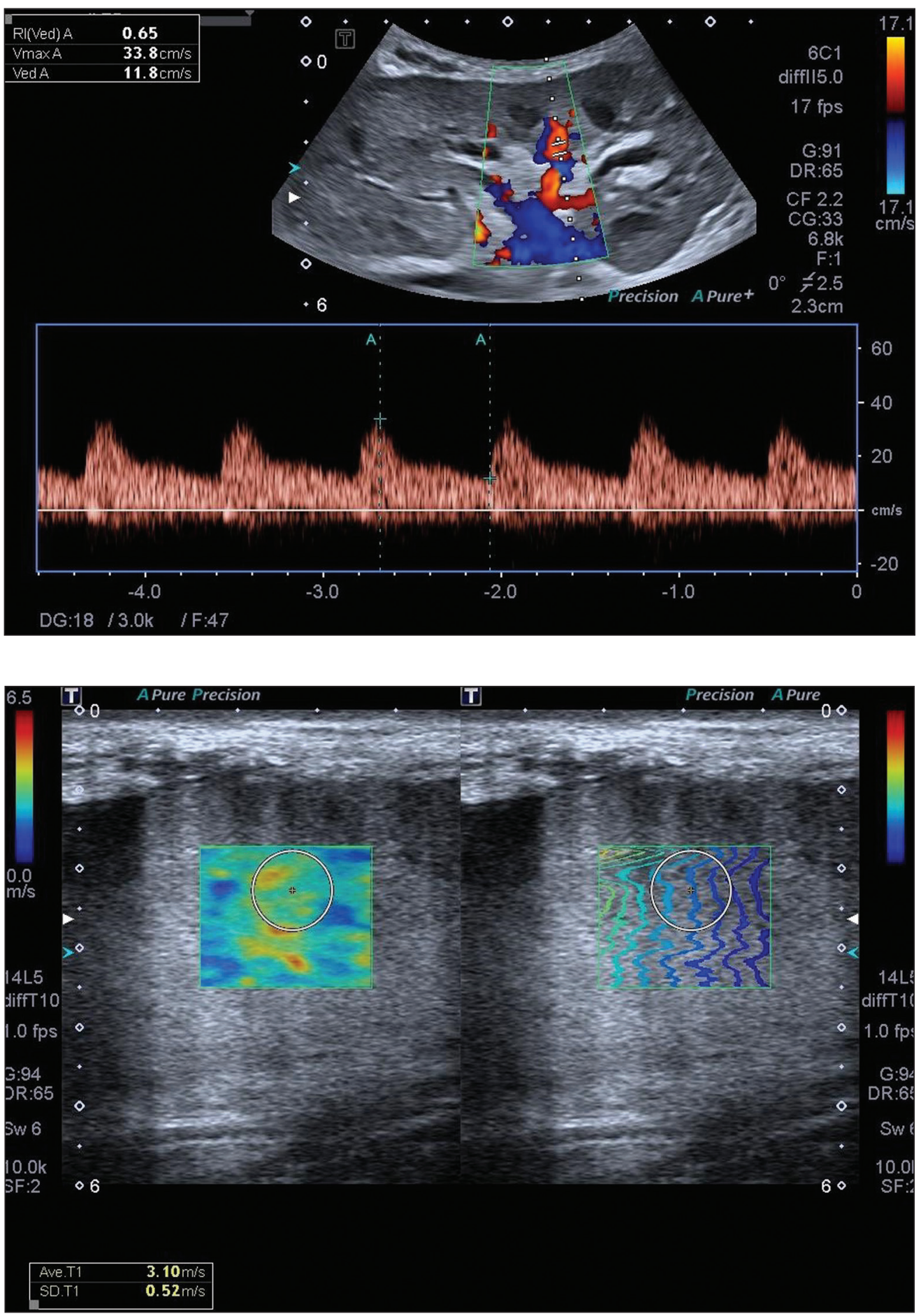

\section{Sample size}

Using the effect size estimated in the study conducted by Chiocchini et al. ${ }^{(22)}$, a total width of 0.15 , a two-sided type I error of 0.05 , and a power of 0.80 , we calculated the sample size required to be 55 subjects $\left(G^{*}\right.$ Power software version 3.1.9.2).

\section{Statistical analysis}

The statistical analysis was performed with the Predictive Analytics Software package, version 18.0 (SPSS
Inc., Chicago, IL, USA). Quantitative variables are expressed as mean \pm standard deviation or as median (interquartile range $[\mathrm{IQR}]$ ), whereas qualitative variables are expressed as absolute and relative frequencies. For analysis purposes, patients were categorized into two groups by renal RI: $<0.79$ (normal, $\mathrm{n}=46$ ) and $\geq 0.79$ (abnormal, $\mathrm{n}=9$ ). A multivariate analysis was performed by using binary logistic regression with generalized linear models to identify the independent variables associated with the Doppler RI. The level of significance was set at $p<0.05$. 


\section{RESULTS}

Between September 2018 and July 2019, 55 patients were enrolled in the study. The mean age was $46,0 \pm 16.4$ years; $38(69.1 \%)$ of the patients were male, and $44(80 \%)$ self-identified as White. Table 1 summarizes the characteristics of the study sample. The median values for glomerular filtration rate and creatinine were $17.3 \mathrm{~mL} / \mathrm{min}$ (IQR, 8.4-28.4 mL/min) and $4 \mathrm{mg} /$ day (IQR, 2.3-6.1 mg/day), respectively. Forty-one patients $(74.5 \%)$ had advanced chronic kidney disease or end-stage renal disease, and 53 (96.4\%) had impaired renal function. Of the 55 patients evaluated, $52(94.5 \%)$ received a kidney from a deceased donor. The mean RI of the main renal artery and mean shear wave velocity were $0.65 \pm 0.08$ and $2.3 \pm 0.4 \mathrm{~m} / \mathrm{s}$, respectively.

Table 2 shows a comparison between the normal RI and abnormal RI groups in terms of the patient characteristics. The mean age was higher in the abnormal RI group than in the normal RI group $(68.0 \pm 8.6$ years vs. $42.6 \pm$ 14.1 years, $p<0.001)$, as was the mean shear wave velocity $(2.6 \pm 0.4 \mathrm{~m} / \mathrm{s}$ vs. $2.2 \pm 0.4 \mathrm{~m} / \mathrm{s}, p=0.013)$. There were no significant differences between the two groups regarding sex, race, estimated glomerular filtration rate, serum creatinine, graft size, and kidney donor type. Multivariate analysis identified two independent predictors of arterial resistance: age $(\mathrm{OR}=1.169 ; 95 \% \mathrm{CI}: 1.056$ to $1.294 ; p=$

Table 1-General characteristics of the kidney transplant recipients evaluated.

\begin{tabular}{lc}
\hline Variable & $(\mathrm{N}=55)$ \\
\hline Age (years), mean \pm SD & $46.0 \pm 16.4$ \\
Male sex, $\mathrm{n}(\%)$ & $38(69.1)$ \\
Race, $\mathrm{n}(\%)$ & \\
$\quad$ White & $44(80.0)$ \\
$\quad$ Black & $11(20.0)$ \\
Donor, $\mathrm{n}(\%)$ & \\
$\quad$ Deceased & $52(94.5)$ \\
$\quad$ Living & $3(5.5)$ \\
eGFR (mL/min/1.73 m²), median (IQR) & $17.3(8.4-28.4)$ \\
Creatinine ( $\mu$ mol/L), median (IQR) & $4.0(2.3-6.1)$ \\
Renal function impairment, $\mathrm{n}(\%)$ & \\
$\quad$ Mild/moderate & $14(25.5)$ \\
$\quad$ Severe & $18(32.7)$ \\
End-stage & $23(41.8)$ \\
Transplanted kidney size (cm), mean $\pm \mathrm{SD}$ & $11.4 \pm 1.2$ \\
\hline
\end{tabular}

$\mathrm{SD}$, standard deviation; eGFR, estimated glomerular filtration rate.
$0.003)$ and shear wave velocity $(\mathrm{OR}=17.1 ; 95 \% \mathrm{CI}: 1.137$ to $257.83 ; p=0.040)$.

\section{DISCUSSION}

We identified a positive association between SWE parameters and arterial resistance in kidney transplant recipients. In addition, age and shear wave velocity were found to be independent predictors of arterial resistance. These findings indicate that SWE can not only quantify tissue elasticity in a renal allograft but also predict arterial resistance.

Determination of the RI is a useful tool in assessing the prognosis for graft survival in the chronic period after transplantation, because it reflects the vascular status of the allograft ${ }^{(23-26)}$. An RI $>0.8$ are usually typical of allograft malfunction and death with a functioning graft ${ }^{(27)}$. $\mathrm{Ba}$ et al. ${ }^{(24)}$ found that an increase $>1$ in the RI could reflect absence of end-diastolic blood flow, resulting in a worse prognosis for renal allograft survival. Recent studies of the extrarenal factors influencing the RI in kidney transplant recipients (e.g., recipient age, arterial stiffness, and left ventricular diastolic function) have demonstrated that the RI is dependent on the vascular characteristics of the recipient ${ }^{(28,29)}$.

Although color Doppler is an established method to assess renal allografts, ultrasound elastography seems to show renal impairment earlier. Kidney stiffness has been used as a predictor of renal allograft fibrosis ${ }^{(30-34)}$. Renal sampling by SWE has been shown to have a reliability of $97.6 \%{ }^{(22)}$. In a study conducted in Turkey, renal parenchymal stiffness correlated positively with the $\mathrm{RI}^{(33)}$. In a study of 50 kidney transplant recipients under clinical suspicion of allograft fibrosis in Italy, a strong correlation was observed between low tissue elasticity and moderate-to-severe interstitial fibrosis ${ }^{(35)}$. In addition, several studies have indicated that an increase in shear wave velocity is predictive of a worsened estimated glomerular filtration rate, as well as renal fibrosis, in kidney transplant recipients ${ }^{(36-38)}$.

Our study has some limitations. First, the post-transplant period was not evaluated. In addition, no biopsies were performed, so we were unable to compare our results with the biopsy findings. Furthermore, all of the results were interpreted by the same examiner. Moreover, there was no control group of healthy patients to rule out the possibility that the advanced age of the patients in our sample was the cause of the abnormal stiffness of the renal

Table 2-Comparison between the kidney transplant recipients with normal and abnormal Rls $(<0.79$ and $\geq 0.79$, respectively), in terms of sociodemographic and clinical variables.

\begin{tabular}{|c|c|c|c|}
\hline Variable & $\mathrm{RI}<0.79(\mathrm{n}=46)$ & $\mathrm{RI} \geq 0.79(\mathrm{n}=9)$ & $P$ \\
\hline Age (years), mean $\pm S D$ & $42.6 \pm 14.4$ & $68,0 \pm 8.7$ & $<0.001$ \\
\hline Creatinine $(\mu \mathrm{mol} / \mathrm{L})$, median (IQR) & $4.0(2.3-6.5)$ & $3.8(2.3-5.8)$ & 0.935 \\
\hline eGFR (mL/min/1.73 $\left.\mathrm{m}^{2}\right)$, median (IQR) & $17.3(7.9-30.8)$ & $16.5(9.2-25.4)$ & 0.806 \\
\hline Transplanted kidney size $(\mathrm{cm})$, mean \pm SD & $11.5 \pm 1.2$ & $11.1 \pm 0.8$ & 0.305 \\
\hline Shear wave velocity $(\mathrm{m} / \mathrm{s})$, mean $\pm \mathrm{SD}$ & $2.2 \pm 0.4$ & $2.6 \pm 0.4$ & 0.038 \\
\hline
\end{tabular}

SD, standard deviation; eGFR, estimated glomerular filtration rate. 
parenchyma. However, to our knowledge, this is the first study to investigate the association between renal stiffness, as assessed by SWE, and arterial RI, as assessed by ultrasound Doppler, in kidney transplant recipients in Brazil.

In conclusion, the stiffness of the renal cortex of a transplanted kidney appears to correlate with arterial resistance in kidney transplant recipients. In addition, monitoring renal allografts by SWE may provide an additional early prognostic index to assess chronic renal dysfunction.

\section{REFERENCES}

1. GBD Chronic Kidney Disease Collaboration. Global, regional, and national burden of chronic kidney disease, 1990-2017: a systematic analysis for the Global Burden of Disease Study 2017. Lancet. 2020;395:709-33.

2. Vanholder R, Stel VS, Jager KJ, et al. How to increase kidney transplant activity throughout European advocacy review by the European Kidney Health Alliance. Nephrol Dial Transplant. 2019;34:1254-61.

3. Axelrod DA, Schnitzler MA, Xiao H, et al. An economic assessment of contemporary kidney transplant practice. Am J Transplant. 2018;18:1168-76.

4. Broecker V, Mengel M. The significance of histological diagnosis in renal allograft biopsies in 2014. Transpl Int. 2015;28:136-45.

5. Marticorena Garcia SR, Guo J, Dürr M, et al. Comparison of ultrasound shear wave elastography with magnetic resonance elastography and renal microvascular flow in the assessment of chronic renal allograft dysfunction. Acta Radiol. 2018;59:1139-45.

6. Cui G, Yang Z, Zhang W, et al. Evaluation of acoustic radiation force impulse imaging for the clinicopathological typing of renal fibrosis. Exp Ther Med. 2014;7:233-5.

7. Fletcher JT, Nankivell BJ, Alexander SI. Chronic allograft nephropathy. Pediatr Nephrol. 2009;24:1465-71.

8. Kim BJ, Kim CK, Park JJ. Non-invasive evaluation of stable renal allograft function using point shear-wave elastography. Br J Radiol. 2018;91:20170372.

9. Köhnke R, Kentrup D, Schütte-Nütgen K, et al. Update on imagingbased diagnosis of acute renal allograft rejection. Am J Nucl Med Mol Imaging. 2019;9:110-26.

10. Ghonge NP, Mohan M, Kashyap V, et al. Renal allograft dysfunction: evaluation with shear-wave sonoelastography. Radiology. 2018 ; 288:146-52.

11. Moraes PHM, Sigrist R, Takahashi MS, et al. Ultrasound elastography in the evaluation of thyroid nodules: evolution of a promising diagnostic tool for predicting the risk of malignancy. Radiol Bras. 2019;52:247-53.

12. Cunha GB, Marino LCI, Yamaya A, et al. Elastography for the evaluation of thyroid nodules in pediatric patients. Radiol Bras. 2019 52:141-7.

13. Rocha SMS. Elastography in the evaluation of thyroid nodules in children - expanding the field of ultrasound to reduce the need for invasive procedures. Radiol Bras. 2019;52(3):v.

14. Silva LCM, Oliveira JT, Tochetto S, et al. Ultrasound elastography in patients with fatty liver disease. Radiol Bras. 2020;53:47-55.

15. Fleury EFC, Marcomini K. Breast elastography: diagnostic performance of computer-aided diagnosis software and interobserver agreement. Radiol Bras. 2020;53:27-33.

16. Järv L, Kull I, Riispere Z, et al. Ultrasound elastography correlations between anthropometrical parameters in kidney transplant recipients. J Investig Med. 2019;67:1137-41

17. Wang HK, Lai YC, Lin YH, et al. Acoustic radiation force impulse imaging of the transplant kidney: correlation between cortical stiffness and arterial resistance in early post-transplant period. Transplant Proc. 2017;49:1001-4.
18. Vandenbroucke JP, von Elm E, Altman DG, et al. Strengthening the Reporting of Observational Studies in Epidemiology (STROBE): explanation and elaboration. PLoS Med. 2007;12:1495-9.

19. Garra BS. Elastography: history, principles, and technique comparison. Abdom Imaging. 2015;40:680-97.

20. Rho JY, Ashman RB, Turner CH. Young's modulus of trabecular and cortical bone material: ultrasonic and microtensile measurements. J Biomech. 1993;26:111-9.

21. Chen S, Urban MW, Pislaru C, et al. Shearwave dispersion ultrasound vibrometry (SDUV) for measuring tissue elasticity and viscosity. IEEE Trans Ultrason Ferroelectr Freq Control. 2009;56:55-62.

22. Chiocchini ALC, Sportoletti C, Comai G, et al. Correlation between renal cortical stiffness and histological determinants by point shear-wave elastography in patients with kidney transplantation. Prog Transplant. 2017;27:346-53.

23. Cano H, Castañeda DA, Patiño N, et al. Resistance index measured by Doppler ultrasound as a predictor of graft function after kidney transplantation. Transplant Proc. 2014;46:2972-4.

24. Ba S, Halimi JM, Al-Najjar A, et al. Prognostic value of absent enddiastolic flow within the first week following renal transplantation. Transplant Proc. 2009;41:645-7.

25. Gómez V, Orosa A, Rivera M, et al. Resistance index determination in the pre and post kidney transplantation time points in graft dysfunction diagnosis. Transplant Proc. 2015;47:34-7.

26. Kramann R, Frank D, Brandenburg VM, et al. Prognostic impact of renal arterial resistance index upon renal allograft survival: the time point matters. Nephrol Dial Transplant. 2012;27:3958-63.

27. Lee PC, Lee CY, Hu RH, et al. Intrarenal vascular resistance parameters in kidney transplant patients receiving calcineurin inhibitor-based or sirolimus-based regimens. Nephrol Dial Transplant. 2010;25:1675-80.

28. Kolonko A, Szotowska M, Kuczera P, et al. Extrarenal factors influencing resistance index in stable kidney transplant recipients. Transplantation. 2013;96:406-12.

29. Naesens M, Heylen L, Lerut E, et al. Intrarenal resistive index after renal transplantation. N Engl J Med. 2013;369:1797-806.

30. Bolboac SD, Elec FI, Elec AD, et al. Shear-wave elastography variability analysis and relation with kidney allograft dysfunction: a single-center study. Diagnostics (Basel). 2020;10:41.

31. Singh H, Panta OB, Khanal U, et al. Renal cortical elastography: normal values and variations. J Med Ultrasound. 2017;25:215-20.

32. Leong SS, Wong JHD, Shah MNM, et al. Shear wave elastography in the evaluation of renal parenchymal stiffness in patients with chronic kidney disease. Br J Radiol. 2018;91:20180235.

33. Ozkan F, Yavuz YC, Inci MF, et al. Interobserver variability of ultrasound elastography in transplant kidneys: correlations with clinicalDoppler parameters. Ultrasound Med Biol. 2013;39:4-9.

34. Wang Z, Yang H, Suo C, et al. Application of ultrasound elastography for chronic allograft dysfunction in kidney transplantation. J Ultrasound Med. 2017;36:1759-69.

35. Orlacchio A, Chegai F, Del Giudice C, et al. Kidney transplant: usefulness of real-time elastography (RTE) in the diagnosis of graft interstitial fibrosis. Ultrasound Med Biol. 2014;40:2564-72.

36. Leong SS, Wong JHD, Shah MN, et al. Comparison of shear wave elastography and conventional ultrasound in assessing kidney function as measured using $51 \mathrm{Cr}$-ethylenediaminetetraacetic acid and 99 Tc-dimercaptosuccinic acid. Ultrasound Med Biol. 2019;45:1417-26.

37. Samir AE, Allegretti AS, Zhu Q, et al. Shear wave elastography in chronic kidney disease: a pilot experience in native kidneys. BMC Nephrol. 2015;31;16:119.

38. Ma MKM, Law HKW, Tse KS, et al. Non-invasive assessment of kidney allograft fibrosis with shear wave elastography: a radiological-pathological correlation analysis. Int J Urol. 2018;25:450-5. 